\title{
GHS-R1a constitutive activity and its physiological relevance
}

\author{
Yves Mear $^{1}$, Alain Enjalbert ${ }^{1,2}$ and Sylvie Thirion ${ }^{1 *}$ \\ CNRS, CRN2M UMR7286, Aix Marseille University, Marseille, France \\ ${ }^{2}$ Molecular Biology Laboratory, Conception Hospital, AP-HM, Marseille, France
}

\author{
Edited by: \\ María M. Malagón, University of \\ Cordoba, Spain \\ Reviewed by: \\ Rhonda D. Kineman, University of \\ Illinois at Chicago, USA \\ Jesus P. Camiña, Hospital Clínico \\ Universitario de Santiago, Spain \\ *Correspondence: \\ Sylvie Thirion, Faculté de Médecine \\ Nord, CRN2M - Neurobiology and \\ Neurophysiological Research Center \\ of Marseille, UMR CNRS 7286, \\ Aix-Marseille University, Bd Pierre \\ Dramard-CS 80011, 13344 Marseille \\ Cedex 15, France \\ e-mail:sylvie.thirion@univ-amu.fr
}

\begin{abstract}
Abundant evidences have shown that ghrelin, by its binding to GHS-R1a, plays an important role for fundamental physiological functions. Increasing attention is given to the GHS-R1a unusually high constitutive activity and its contribution to downstream signaling and physiological processes. Here, we review recent lines of evidences showing that the interaction between ligand-binding pocket TM domains and the ECL2 could be partially responsible for this high constitutive activity. Interestingly, GHSR-1a constitutive activity activates in turn the downstream PLC, PKC, and CRE signaling pathways and this activation is reversed by the inverse agonist [D-Arg ${ }^{1}, \mathrm{D}-\mathrm{Phe}^{5}, \mathrm{D}-\mathrm{Trp}^{7,9}$, Leu ${ }^{11}$-substance $P$ (MSP). Noteworthy, GHSR-1a exhibits a C-terminal-dependent constitutive internalization. Non-sense GHS-R1a mutation (Ala204Glu), first discovered in Moroccan patients, supports the role of GHSR-1a constitutive activity in physiological impairments. Ala204Glu-point mutation, altering exclusively the GHSR-1a constitutive activity, was associated with familial short stature syndrome. Altogether, these findings suggest that GHS-R1a constitutive activity could contribute to GH secretion or body weight regulation. Consequently, future research on basic and clinical applications of GHS-R1a inverse agonists will be challenging and potentially rewarding.
\end{abstract}

Keywords: ghrelin receptor, GPCR, constitutive activity, signaling pathway, PLC, $\beta$-arrestin

\section{INTRODUCTION}

The secretion of growth hormone (GH) by the anterior pituitary is under complex control. Small synthetic molecules termed GH secretagogues (GHS) are synthetic, peptidyl, and nonpeptidyl molecules which possess strong and dose-dependent GH-releasing activity in vivo in several species and in humans (Cheng et al., 1989; Bowers et al., 1991; Cheng et al., 1991). The cloning of the GH secretagogue receptor (GHS-R1a, now called ghrelin receptor) in 1996 (Howard et al., 1996; Pong et al., 1996), led to the isolation of the endogenous ligand, ghrelin in 1999 (Kojima et al., 1999).

Ghrelin is a 28 amino acid peptide that differs from all other peptide hormones known by an octanoylation. This fatty acid modification is essential both for the binding to and activation of the receptor and for its pharmacokinetic properties (Kojima et al., 2001). Ghrelin strongly stimulates GH release in humans (Bowers et al., 1991), and it is much more potent than Growth HormoneReleasing Hormone (GHRH) under similar conditions. Ghrelin potently increase food intake and weight gain, and also regulates energy homeostasis and metabolism following central and systemic administration (Castañeda et al., 2010; Stengel and Taché, 2012).

The GHS-R1a is a G protein-coupled receptor (GPCR) of 366 amino acids with the characteristic seven transmembranespanning domains (7TM receptor; for review Schwartz et al., 2006; Cruz and Smith, 2008). Signal transduction from the extracellular environment via 7TM receptors in general requires a conformational change from an inactive $(\mathrm{R})$ to a active state $\left(\mathrm{R}^{*}\right)$.
Certain 7TM receptors are stabilized in an active conformation without any ligand present. The ability to propagate the intracellular signal in the absence of agonist is commonly known as constitutive activity.

Constitutive activity is described for mostly all GPCR, however for a large part of them the level of constitutive activity is very low (Arvanitakis et al., 1998; Smit et al., 2007).

The GHS-Rla exhibits unusual high constitutive activity (Holst et al., 2003) as it signal with $\sim 50 \%$ of its maximal capacity in the absence of the agonist, ghrelin. This article aims to review the current knowledge on GHS-R1a ligand-independent constitutive activity and its functions.

\section{GHS-R1a AND ITS CONSTITUTIVE ACTIVITY MOLECULAR BASIS}

For several years, it has been noted that mostly all GPCRs exhibit intrinsic constitutive activity (Arvanitakis et al., 1998; Smit et al., 2007). In 1999, studies performed on the $\beta_{2}$-adrenergic receptor suggested that this ligand-independent activity could involve an inward movement of the extracellular segments of the transmembrane domains (TMs) VI and VII toward TM III in the ligand-binding pocket (Elling et al., 1999).

Holst and colleagues performed a structural analysis of GHSR1a and revealed the crucial role of an aromatic cluster formed by three residues (Phe VI:16, Phe VII:06, and Phe VII:09) on the inner face of the extracellular ends of GHS-R1a TMs VI and VII. Their close spatial proximity and the formation of this cluster allow GHS-R1a to stabilize in its active conformation in 
absence of agonist (Holst et al., 2004; Mokrosinski and Holst, 2010).

The residue in position VI:16 is central for the constitutive activity level that can gradually be increased or decreased depending on the size and hydrophobic properties of the side chain of the amino acid. It has also been suggested that the aromatic residue VI:16 may work as a tethered agonist located strategically at the interface between TM III TM VI and TM VII, blocking these extracellular TM segments in a conformation promoting GHS-R1a high constitutive activity (Schwartz et al., 2006).

A conserved aromatic lock crucial for GHS-R1a high basal signaling level is formed by the Trp VI:13 and Phe V:13 residues (Holst et al., 2004). The Trp VI:13 (=Trp276) is located in the conserved motif CWxP in the middle of TM VI and is supposed to act as a global toggle switch model allowing the inward movement of this domain, and the GHS-R1a high basal activation level (Schwartz et al., 2006; Floquet et al., 2010).

Specific residues in the vinicity of this cluster have been proposed to orchestrate finely tuned microswitches critical for the activation level in absence of ligand (Holst et al., 2004; ValentinHansen et al., 2012).

In order to study the importance of this core peptide in the GHS-R1a constitutive activity, Gozé et al. introduced the mutation Trp276Ala and mutated the two surrounding amino acid residues Val131 and Ile134. Their results revealed that the mutation Trp276Ala dramatically impairs the ligand-independent activity whereas Val131Leu and Ile134Met highly increase GHSR1a basal activity. According to these results, the three residues Trp276, Val131, and Ile134 could also significantly impact on GHS-R1a constitutive signaling (Gozé et al., 2010).

In 2006, Pantel et al. reported a mutation (Ala204Glu) in the extracellular loop II (ECL2) of the human GHS-R1a affecting selectively the ligand-independent activity (Pantel et al., 2006). The ECL2 structure function analysis revealed that by restricting this segment, and so possibly TM V/TM III, movements either by mutation or by ligand binding, reduces the constitutive signaling level (Mokrosinski et al., 2012), showing that the high GHS-R1a basal signaling level depends on the flexibility in these segments. Other studies showed that a single mutation or space generating a substitution in the GHS-R1a sequence or in the ligand peptide sequence can change the ligand properties from agonist to inverse agonist or from inverse agonist to agonist depending on the residue mutated (Holst et al., 2007; Els et al., 2012).

TM VI and TM VII movements into their inward-bend promoting the ligand-independent active conformation can be stoically blocked, using a modified substance P (MSP) inverse agonist, [D-Arg $\left.{ }^{1}, \mathrm{D}-\mathrm{Phe}^{5}, \mathrm{D}-\mathrm{Trp}^{7,9}, \mathrm{Leu}^{11}\right]$-substance P (often referred in the literature as SPA, for substance $\mathrm{P}$ analog). The systematic analysis of this peptide structure-function relationship identified the C-terminal heptapeptide ( $\mathrm{fQwFwLL}$ ) as its active core, the D-Phe ${ }^{5}$ residue being apparently crucial for the inverse agonist property and the binding affinity (Holst et al., 2006). Unlike ghrelin that only interacts with the middle part of the ligand-binding pocket, the inverse agonist binds to an extended-binding pocket comprising all the seven TM domains of the receptor except for the first one. In addition, the spacegenerating mutants located relatively deep in the binding pocket at key positions within the TM III, TM IV, and TM V, upregulate the effects of MSP, suggesting that this molecule could prevent the spontaneous receptor activation across the binding pocket extend (Holst et al., 2006; Mokrosinski and Holst, 2010).

\section{INTRACELLULAR PATHWAYS AND CONSTITUTIVE INTERNALIZATION}

Inositol phosphate (IP) signaling pathway, through Phospholipase C (PLC) activation, was the first specifically associated with the GHS-R1a ligand-dependent activity (Adams et al., 1995; Lei et al., 1995; Chen et al., 1996; Petersenn, 2002) inducing intracellular calcium mobilization (Herrington and Hille, 1994). Consequently, this pathway has been investigated for determining the receptor constitutive signaling. PLC activation was demonstrated comparing heterologous HEK-293 and COS-7 cells overexpressing the GHS-R1a to cells transfected with the motilin receptor (that is the closest GPCR homolog of GHS-R1a without constitutive activity; Holst et al., 2003). The unusualy high GHS-R1a ligand-independent signaling level was similar to that of the most famous highly constitutively active GPCR, the virally encoded ORF74 receptor. To note, this paper allowed characterizing MSP as a full GHS-R1a inverse agonist. Indeed, this compound inhibits the GHS-Rla constitutive ligand-independent IP accumulation and decreases the IP level to that of cells transfected with the empty vector (Holst et al., 2003). Lau et al. reported that GHS-R1a constitutive activity could reduce apoptosis in HEK-293 overexpressing the (seabream) sbGHS-R1a, through PKC-dependent caspase-3 inhibition (Lau et al., 2009).

Gq/11-coupled GHS-R1a constitutive activity also resulted in a dose-dependent but ligand-independent increase in the CRE luciferase reporter while the full inverse agonist MSP partially reversed this effect. To note, heterotrimeric Gq/11 protein-coupled receptors have previously been reported to phosphorylate the cAMP responsive element-binding protein (CREB) by activating the CRE pathway as a result of calcium/calmoduline kinase IV (CaMK IV) and/or protein kinase C (PKC) activation (Matthews et al., 1994; Poulin et al., 2009) (Figure 1). Finally, performing serum responsive element (SRE) reporter assay on HEK-293 cells transfected with GHS-R1a revealed a 10-fold increase in the ligand-independent signaling compared to the cells transfected with the empty plasmid.

While many other signaling pathways have been shown to play a role in the GHS-R1a ligand-dependent activation, the GHS-R1a ligand-independent activation has not been investigated. Indeed, Gi/o heterotrimeric pathway was clearly associated with beta-arrestin-mediated ERK1/2 activation following GHSR1a activation by ghrelin (Camiña et al., 2007). Similarly, c-Src that is involved in the GHS-R1a ghrelin-dependent Akt activation (via Gi/o-protein; Lodeiro et al., 2009) has not been studied for the high basal level associated signaling pathways.

Since GHS-R1a exhibits an unusually high constitutive activity, it could be hypothesized that the downstream signaling level could reflect the membrane expression level. In this context, a better understanding of the mechanisms underlying and modulating its plasma membrane expression was necessary. To this end, GHS-R1a was tagged using M2 anti-FLAG antibody labeling, thus allowing following the intracellular movement of 


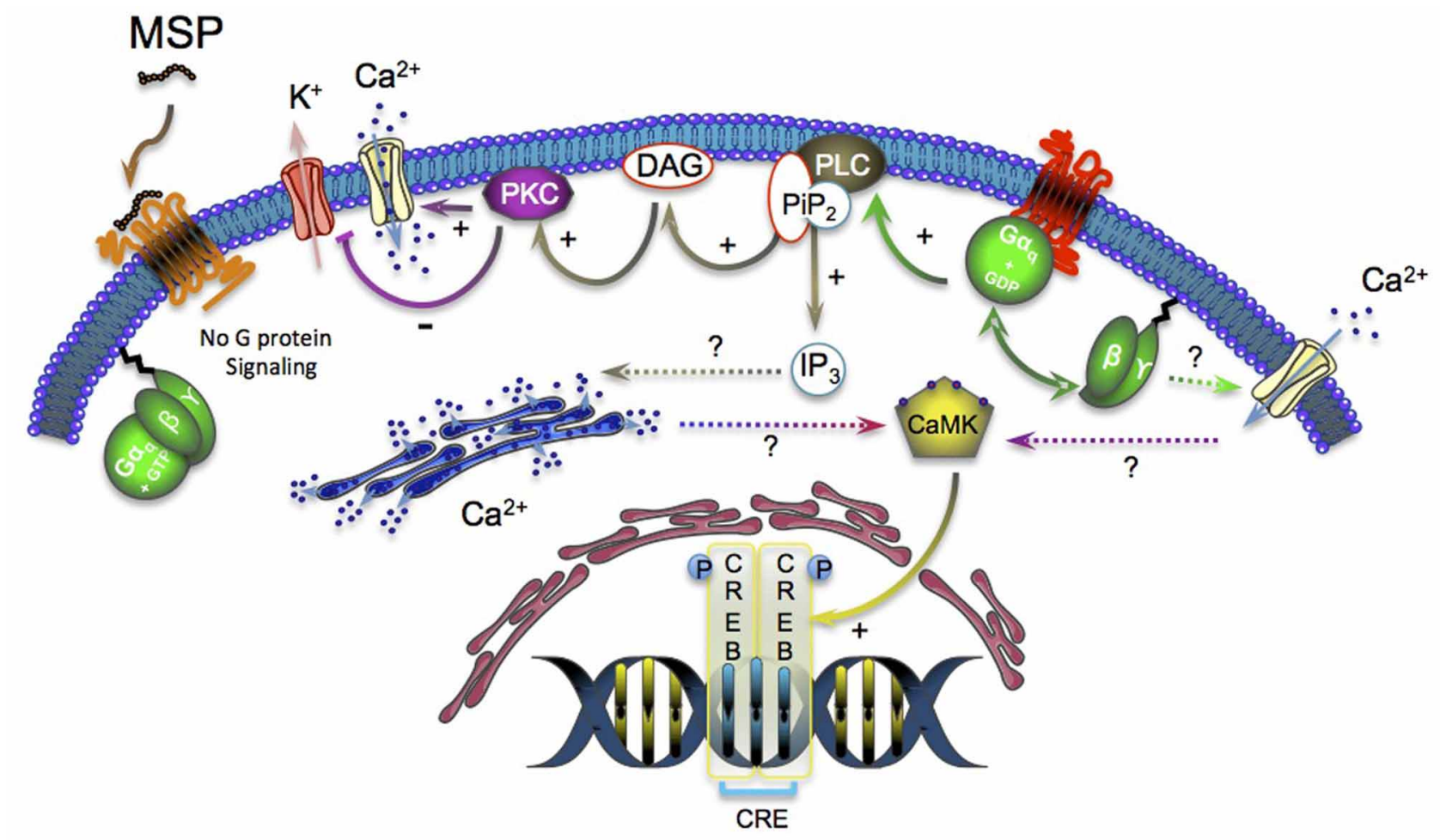

FIGURE 1 | GHS-R1a constitutive activity leads to the dissociation of $\alpha$ and $\beta \gamma$ subunits of heterotrimeric G-proteins. The free Gq subunit activates the PLC that cleaves $\mathrm{PiP}_{2}$ into IP3 and DAG. DAG activates the PKC, which in turn actives the $\mathrm{Ca}^{2+}$ channels and inhibits the $\mathrm{K}^{+}$channels (continuous line). The effects of IP3 on the intracellular $\mathrm{Ca}^{2+}$ mobilization and the origin of the $\mathrm{Ca}^{2+}$ that activates the $\mathrm{Ca}^{2+}$ calmodulin kinase (CaMK) remain unclear and will need further investigations (dotted line). The binding of the inverse agonist MSP to the GHS-R1a inhibits the G-protein signaling and decreases the IP3 (via PLC) and CRE pathway (via phosphorylated CREB) constitutive activation.
GHS-R1a. These experiments revealed a GHS-R1a constitutive ligand-independent internalization and the receptor could be trapped at the cell surface by the inverse agonist MSP. The punctiform receptor intracellular labeling co-localizes with clathrincoated vesicles and recycling endosome markers (Holst et al., 2003).

Unlike the GHS-R1a, GPR-39 receptor, a member of the ghrelin receptor family, is not constitutively internalized but it displays a high ligand-independent signaling level (Holst et al., 2003). Based on these observations, Holliday et al. developed an elegant approach by switching the GHS-R1a C tail with that of the GPR-39. The chimera, named GhR-39, was constitutively active through the PLC pathway but its internalization was impaired. Components supporting the constitutive activity could be necessary but not sufficient for GHS-R1a endocytosis and additional regulatory elements in the $\mathrm{C}$-terminal domain may be involved (Holliday et al., 2007).

GHS-R1a constitutive internalization requires the sequential activation of the monomeric G proteins Rab5 and Rab11. Rab proteins control various important cellular processes, such as endocytosis, trafficking, endosome fusion. and exocytosis (Seachrist and Ferguson, 2003). These proteins regulate vesicle transport and fusion with specific target compartments, the early endosomes for Rab5, and the endosomal recycling compartments such as the perinuclear recycling compartment (PNRC) for Rab11. MSP-induced GHS-R1a membrane plasma anchorage is blocked by the constitutive expression of GTP-binding mutants of Rabs (Rab5 Gln79Leu or Rab11 Gln70Leu) confirming that MSP naturally inhibits GHS-R1a internalization rather than activates GHS-R1a neosynthesis and trafficking (Holliday et al., 2007).

$\beta$-arrestin recruitment has been obviously investigated as it appears as the most widely standard adaptor for GPCR endocytosis (Lefkowitz, 1998) (Figure 2). Only ghrelin stimulation induces GHSR-1a phosphorylation and $\beta$-arrestin 2 recruitment. Besides, dominant-negative $\beta$-arrestin 2 construct, which competes for clathrin interaction, does not inhibit the constitutive endocytosis, supporting the hypothesis of a GHS-R1a $\beta$-arrestinindependent constitutive internalization. These results suggest that the aromatic residue VI:16, already mentioned above, could act as "tethered biased agonist" rather than "tethered agonist" because it blocks the receptor in a conformation that only induces the $\mathrm{Gq} / 11$ protein activation without $\beta$-arrestin 2 recruitment (Shukla et al., 2011; Reiter et al., 2012). To note, $\beta$-arrestin 2 recruitment has been reported to active the MAPK pathway. In this context, the absence of $\beta$-arrestin 2 recruitment in basal condition has been proposed to explain the absence of MAPK pathway activation (Holliday et al., 2007).

Purified GHS-R1a monomers in a lipid disc showed that the ghrelin receptor per se activates $\mathrm{Gq} / 11$ in the absence of agonist, 


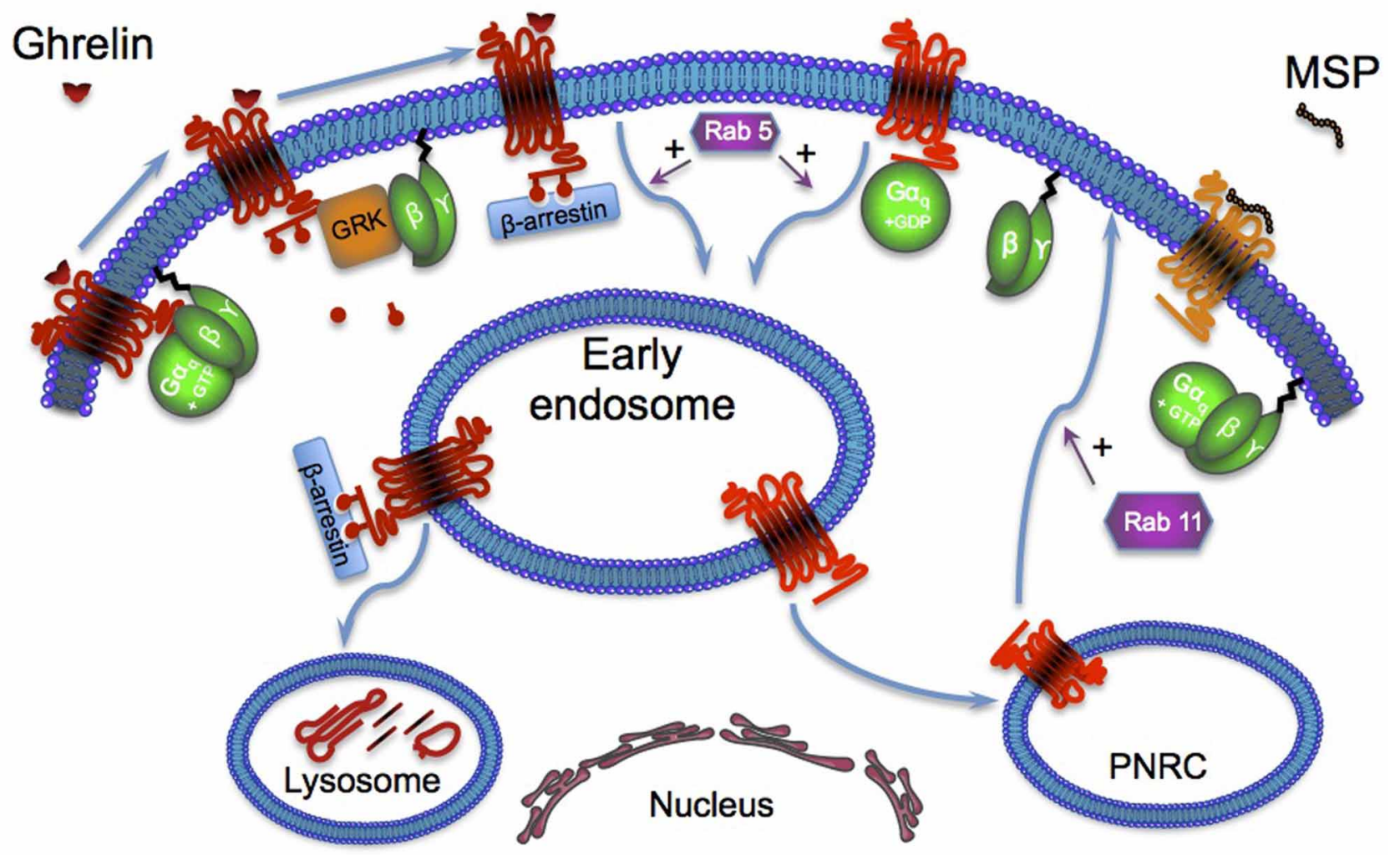

FIGURE 2 | GHS-R1a activation by its endogenous ligand ghrelin leads to the dissociation of $\alpha$ and $\beta \gamma$ subunits of heterotrimeric G-proteins. The $\beta \gamma$ dimer recruits G-protein-receptor kinases (such as $\mathrm{GRK}_{2}$ or $\mathrm{GRK}_{3}$ ) to the receptor, where they phosphorylate the agonist-bound receptor. These phosphorylations lead to the recruitment of $\beta$-arrestins and activation of the monomeric G-protein $R A b_{5}$ that targets the receptor to early endosomes.
Then the receptor is addressed to the lysosome for degradation. GHS-R1a constitutive activation recruits $\mathrm{Rab}_{5}$ without activation of the GRK, inducing subsequent phosphorylation and $\beta$-arrestin recruitment. This constitutive activation of Rab $b_{5}$ explains the receptor ligand-independent internalization that is first addressed to the early endosome then to the PNRC (perinuclear recycling compartment) where it activates the monomeric G-protein Rab ${ }_{11}$. and that GHS-R1a constitutive activity is an intrinsic property of the protein and is not influenced by its cellular environment (Damian et al., 2012). In this context, the receptor isolated in lipid discs recruits arrestin-2 in an agonist-dependent manner (Mary et al., 2012), whereas it interacts with $\mu$-AP2 (plasma membranelocalized clathrin adaptor subunit) in the absence of ligand or in the presence of ghrelin (Damian et al., 2012). Thus, $\mu$-AP2 could be involved in the basal regulation of GHS-R1a trafficking.

\section{PHYSIOLOGICAL RELEVANCE}

Many types of GPCR display a high ligand-independent signaling in vitro (Seifert and Wenzel-Seifert, 2002). Among them, GHS-R1a has been shown to display both the highest basal activation of Gq/11 (about 50\% of its maximal activity) in vitro (Holst et al., 2004), and substantial basal signaling for food intake and weight control in vivo (Petersen et al., 2009; Els et al., 2012). Pantel et al., who reported naturally occurring mutations in the GHS-R1a sequence, have first shown a putative link with physiological impairments in 2006. They reported a substitution mutation located within the first GHS-R1a exon, predicting the substitution of Alanine by Glutamate (Ala204Glu) in two independent Moroccan families. This missense mutation is located in the GHS-R1a ECL2 and affects a fully conserved amino acid. HEK-293 cells stably transfected with WT and Ala204Glumutant GHS-R1a showed, using POU1F1-luciferase reporter assay that this mutation selectively abolishes the GHS-R1a ligandindependent signaling without altering the Ghrelin-dependent activity. Noteworthy, mutations altering exclusively the constitutive activity are associated with familial short stature syndrome and the latter can be partially reversed with GH treatment (Pantel et al., 2006, 2009; Inoue et al., 2011). Wang reported another uncharacterized GHS-R1a mutation affecting the Phe 279 residue (Phe VI:16) recently identified as being of particular interest for GHS-R1a constitutive activity. Noteworthy, the phenotype of patients expressing this mutation is characterized by an increased obesity and short stature (Wang, 2004). Regarding these different but functionally similar mutations, Holst and Schwartz proposed that the absence of GHS-R1a constitutively active signaling results in a syndrome, characterized, not only by a short stature, but also by obesity (Holst and Schwartz, 2006). This suggestion has been confirmed recently using icv MSP administration that significantly decreased the food intake, body weight, and neuropeptide $\mathrm{Y}$ (NPY) and uncoupling protein 2 (UCP2) gene expression in the hypothalamus (Petersen et al., 2009). 
Ligand-dependent GHS-R1a heterodimerizations have been reported for the subtype 1 dopamine receptor that increases dopamine signaling (Jiang et al., 2006), the somatostatin receptor5 that regulates insulin release (Park et al., 2012) and the melanocortin-3 receptor that is involved in body weight regulation and energy balance (Rediger et al., 2011, 2012). Also, the dimerization of the GHS-R1a with the dopamine D2 receptor has recently been shown to regulate appetite (Kern et al., 2012).

Its dimerization with the melanocortin- 3 receptor, the D1 receptor, and the newly discovered $5-\mathrm{HT}_{2 \mathrm{C}}$ receptor may be central in modulating and controlling GHS-R1a-mediated downstream signaling and subsequent satiety and appetite signaling, as well as the rewarding and motivational aspects of food intake (Schellekens et al., 2013). The understanding of the underlying mechanisms leading to these activations may ultimately lead to the development of new therapeutic strategies.

On the other hand, ghrelin and GHS-R1a knockout mice explorations may allow the emergence of new regulatory properties of the ghrelin receptor constitutive activity. For example, GHS-R1a constitutive activity increases limbic seizures in rodents, the endogenous ligand being naturally anticonvulsive (Portelli et al., 2012). In the mouse brain, deficits in spontaneous receptor activity cause marked functional impairment in learning and memory (Albarran-Zeckler et al., 2012). GHS-R1a signaling is necessary for hippocampal-dependent learning and habituated feeding responses (Davis et al., 2011). Ghrelin plays also a role in sleep whereas the GHS-R1a will be more implicated in arousal (Esposito et al., 2012).

To move beyond putative redundant compensation mechanisms, further in vivo investigations targetting the receptor constitutive activity with appropriate pharmacological tools (Mokrosinski and Holst, 2010; Sivertsen et al., 2011) would be needed to determine the underlying physiological functions linked to this constitutive activity.

\section{CONCLUSION}

Abundant evidence currently indicates that ghrelin, by its binding to GHS-R1a, plays a role in various physiological functions that

\section{REFERENCES}

Acunzo, J., Thirion, S., Roche, C., Saveanu, A., Gunz, G., Germanetti, A. L., et al. (2008). Somatostatin receptor sst2 decreases cell viability and hormonal hypersecretion and reverses octreotide resistance of human pituitary adenomas. Cancer Res. 68, 10163-10170.

Adams, E. F., Petersen, B., Lei, T., Buchfelder, M., and Fahlbusch, R. (1995). The growth hormone secretagogue, L-692, 429, induces phosphatidylinositol hydrolysis and hormone secretion by human pituitary tumors. Biochem. Biophys. Res. Commun. 208, 555-561.

Akamizu, T., and Kangawa, K. (2012). The physiological significance and potential clinical applications of

led to the development of clinical trials to translate basic research findings to human disease treatment and diagnosis (for review Akamizu and Kangawa, 2012). Concerning the GHS-R1a constitutive activity, most of the studies performed so far focused on the molecular aspects. Even if some physiological relevance are emerging for food intake regulation (see paragraph above), further studies remain necessary to confirm the role played by the GHS-R1a constitutive activity in the regulation of the GH axis. Pituitary somatotroph adenomas express higher GHS-R1a transcript and protein levels than normal pituitary (Korbonits et al., 1998; Barlier et al., 1999). Moreover, Pantel et al. (2006) have shown that a reduced GHS-R1a constitutive activity impairs the GH secretion. Thus, it should be interesting to test if the GHSR1a constitutive activity disrupts the GH hypersecretion observed in acromegalic patients with somatotroph tumors (Acunzo et al., 2008; Roche et al., 2012).

The signaling pathways associated with this high constitutive activity should also be addressed. Knowing that the heterogeneity of the coupling on the signaling varies depending on the tissue or cell type, it is crucial to address now these questions in physiological or pathophysiological models. Depending on the model, does the GHS-Rla ligand-independent CRE activation pass through the calcium/calmodulin kinase? And/or via the cAMP/PKA pathways?

These issues are part of the many questions pending in this field. Some of them may support the development of clinical applications of GHS-R1a inverse agonists in physiological disorders in the future, allowing developing novel and unique therapies for various disorders, including intractable and serious diseases. Indeed, research on basic and clinical applications of GHS-R1a inverse agonists will be challenging and potentially rewarding.

\section{ACKNOWLEDGMENTS}

We thank very gratefully Prof. Isabelle Limon for helpful criticisms and careful corrections of the manuscript. We acknowledge Dr. Marie-Pierre Blanchard for her manuscript reading. This work was supported by Aix-Marseille University and CNRS.

polymerase chain reaction, triple in-situ hybridization and cell culture studies. J. Neuroendocrinol. 11, 491-502.

Bowers, C. Y., Sartor, A. O., Reynolds, G. A., and Badger, T. M. (1991). On the actions of the growth hormonereleasing hexapeptide, GHRP. Endocrinology 128, 2027-2035.

Camiña, J. P., Lodeiro, M., Ischenko, O., Martini, A. C., and Casanueva, F. F. (2007). Stimulation by ghrelin of $\mathrm{p} 42 / \mathrm{p} 44$ mitogen-activated protein kinase through the GHS-R1a receptor: role of G-proteins and beta-arrestins. J. Cell. Physiol. 213, 187-200.

Castañeda, T. R., Tong, J., Datta, R., Culler, M., and Tschöp, M. H. (2010). Ghrelin in the regulation of body weight and metabolism.
Front. Neuroendocrinol. 31, 44-60. doi: 10.1016/j.yfrne.2009.10.008

Chen, C., Wu, D., and Clarke, I. J. (1996). Signal transduction systems employed by synthetic GHreleasing peptides in somatotrophs. J. Endocrinol. 148, 381-386.

Cheng, K., Chan, W. W., Barreto, A., Convey, E. M., and Smith, R. G. (1989). The synergistic effects of His-D-Trp-Ala-Trp-D-PheLys-NH2 on growth hormone (GH)-releasing factor-stimulated $\mathrm{GH}$ release and intracellular adenosine $3^{\prime}, 5^{\prime}$-monophosphate accumulation in rat primary pituitary cell culture. Endocrinology 124, 2791-2798.

Cheng, K., Chan, W. W., Butler, B., Barreto, A., and Smith, R. G. (1991). Evidence for a role of protein 
kinase-C in His-D-Trp-Ala-Trp-DPhe-Lys-NH2-induced growth hormone release from rat primary pituitary cells. Endocrinology 129, 3337-3342.

Cruz, C. R. Y., and Smith, R. G. (2008). The growth hormone secretagogue receptor. Vitam. Horm. 77, 47-88.

Damian, M., Marie, J., Leyris, J. P., Fehrentz, J. A., Verdié, P., Martinez, J., et al. (2012). High constitutive activity is an intrinsic feature of ghrelin receptor protein: a study with a functional monomeric GHS$\mathrm{R} 1 \mathrm{a}$ receptor reconstituted in lipid discs. J. Biol. Chem. 287, 3630-3641.

Davis, J. F., Choi, D. L., Clegg, D. J., and Benoit, S. C. (2011). Signaling through the ghrelin receptor modulates hippocampal function and meal anticipation in mice. Physiol. Behav. 103, 39-43.

Elling, C. E., Thirstrup, K., Holst, B., and Schwartz, T. W. (1999). Conversion of agonist site to metal-ion chelator site in the beta(2)-adrenergic receptor. Proc. Natl. Acad. Sci. U.S.A. 96, 12322-12327.

Els, S., Schild, E., Petersen, P. S., Kilian, T. M., Mokrosinski, J., Frimurer, T. M., et al. (2012). An aromatic region to induce a switch between agonism and inverse agonism at the ghrelin receptor. J. Med. Chem. 55, 7437-7449.

Esposito, M., Pellinen, J., Kapás, L., and Szentirmai, É. (2012). Impaired wake-promoting mechanisms in ghrelin receptor-deficient mice. Eur. J. Neurosci. 35, 233-243.

Floquet, N., M'Kadmi, C., Perahia, D., Gagne, D., Bergé, G., Marie, J., et al. (2010). Activation of the ghrelin receptor is described by a privileged collective motion: a model for constitutive and agonist-induced activation of a sub-class A G-protein coupled receptor (GPCR). J. Mol. Biol. 395, 769-784.

Gozé, C., Bergé, G., M’Kadmi, C., Floquet, N., Gagne, D., Galleyrand, J. C., et al. (2010). Involvement of tryptophan W276 and of two surrounding amino acid residues in the high constitutive activity of the ghrelin receptor GHS-R1a. Eur. J. Pharmacol. 643, 153-161.

Herrington, J., and Hille, B. (1994). Growth hormone-releasing hexapeptide elevates intracellular calcium in rat somatotropes by two mechanisms. Endocrinology 135, 1100-1108.

Holliday, N. D., Holst, B., Rodionova, E. A., Schwartz, T. W., and Cox, H. M. (2007). Importance of constitutive activity and arrestinindependent mechanisms for intracellular trafficking of the ghrelin receptor. Mol. Endocrinol. 21, 3100-3112.

Holst, B., Cygankiewicz, A., Jensen, T. H., Ankersen, M., and Schwartz, T. W. (2003). High constitutive signaling of the ghrelin receptoridentification of a potent inverse agonist. Mol. Endocrinol. 17, 2201-2210.

Holst, B., Holliday, N. D., Bach, A., Elling, C. E., Cox, H. M., and Schwartz, T. W. (2004). Common structural basis for constitutive activity of the ghrelin receptor family. J. Biol. Chem. 279, 53806-53817.

Holst, B., Lang, M., Brandt, E., Bach, A., Howard, A., Frimurer, T. M., et al. (2006). Ghrelin receptor inverse agonists: identification of an active peptide core and its interaction epitopes on the receptor. Mol. Pharmacol. 70, 936-946.

Holst, B., Mokrosinski, J., Lang, M., Brandt, E., Nygaard, R., Frimurer, T. M., et al. (2007). Identification of an efficacy switch region in the ghrelin receptor responsible for interchange between agonism and inverse agonism. J. Biol. Chem. 282, 15799-15811.

Holst, B., and Schwartz, T. W. (2006). Ghrelin receptor mutations- too little height and too much hunger. J. Clin. Invest. 116, 637-641.

Howard, A. D., Feighner, S. D., Cully, D. F., Arena, J. P., Liberator, P. A., Rosenblum, C. I., et al. (1996). A receptor in pituitary and hypothalamus that functions in growth hormone release. Science 273, 974-977.

Inoue, H., Kangawa, N., Kinouchi, A., Sakamoto, Y., Kimura, C., Horikawa, R., et al. (2011). Identification and functional analysis of novel human growth hormone secretagogue receptor (GHSR) gene mutations in Japanese subjects with short stature. J. Clin. Endocrinol. Metab. 96, E373-E378.

Jiang, H., Betancourt, L., and Smith, R. G. (2006). Ghrelin amplifies dopamine signaling by cross talk involving formation of growth hormone secretagogue receptor/dopamine receptor subtype 1 heterodimers. Mol. Endocrinol. 20, 1772-1785.

Kern, A., Albarran-Zeckler, R., Walsh, H. E., and Smith, R. G. (2012). Apoghrelin receptor forms heteromers with DRD2 in hypothalamic neurons and is essential for anorexigenic effects of DRD2 agonism. Neuron 73, 317-332.

Kojima, M., Hosoda, H., Date, Y., Nakazato, M., Matsuo, H., and Kangawa, K. (1999). Ghrelin is a growth-hormone-releasing acylated peptide from stomach. Nature 402 , 656-660.

Kojima, M., Hosoda, H., Matsuo, H., and Kangawa, K. (2001). Ghrelin: discovery of the natural endogenous ligand for the growth hormone secretagogue receptor. Trends Endocrinol. Metab. 12, 118-122.

Korbonits, M., Jacobs, R. A., Aylwin, S. J., Burrin, J. M., Dahia, P. L., Monson, J. P., et al. (1998). Expression of the growth hormone secretagogue receptor in pituitary adenomas and other neuroendocrine tumors. J. Clin. Endocrinol. Metab. 83, 3624-3630.

Lau, P. N., Chow, K. B. S., Chan, C. B., Cheng, C. H. K., and Wise, H. (2009). The constitutive activity of the ghrelin receptor attenuates apoptosis via a protein kinase C-dependent pathway. Mol. Cell. Endocrinol. 299, 232-239.

Lefkowitz, R. J. (1998). G Proteincoupled Receptors. J. Biol. Chem. 273, 18677-18680.

Lei, T., Buchfelder, M., Fahlbusch, R., and Adams, E. F. (1995). Growth hormone releasing peptide (GHRP6) stimulates phosphatidylinositol (PI) turnover in human pituitary somatotroph cells. J. Mol Endocrinol. 14, 135-138.

Lodeiro, M., Theodoropoulou, M., Pardo, M., Casanueva, F. F., and Camiña, J. P. (2009). c-Src regulates Akt signaling in response to ghrelin via beta-arrestin signalingindependent and -dependent mechanisms. PLoS ONE 4:e4686. doi: 10.1371/journal.pone.0004686

Mary, S., Damian, M., Louet, M. Floquet, N., Fehrentz, J., Marie, J., et al. (2012). Ligands and signaling proteins govern the conformational landscape explored by a $\mathrm{G}$ proteincoupled receptor. Proc. Natl. Acad. Sci. U.S.A. 109, 8304-8309.

Matthews, R. P., Guthrie, C. R., Wailes, L. M., Zhao, X., Means, A. R., and McKnight, G. S. (1994). Calcium/calmodulindependent protein kinase types II and IV differentially regulate CREB-dependent gene expression. Mol. Cell. Biol. 14, 6107-6116.

Mokrosinski, J., Frimurer, T. M., Sivertsen, B., Schwartz, T. W., and Holst, B. (2012). Modulation of constitutive activity and signaling bias of the ghrelin receptor by conformational constraint in the second extracellular loop. J. Biol. Chem. 287, 33488-33502.

Mokrosinski, J., and Holst, B. (2010). Modulation of the constitutive activity of the ghrelin receptor by use of pharmacological tools and mutagenesis. Methods Enzymol. 484, 53-73.

Pantel, J., Legendre, M., Cabrol, S., Hilal, L., Hajaji, Y., Nivot, S., et al. (2006). Loss of constitutive activity of the growth hormone secretagogue receptor in familial short stature. J. Clin. Invest. 116, 760-768.

Pantel, J., Legendre, M., Nivot, S., Morisset, S., Vie-Luton, M. P., Le Bouc, Y., et al. (2009). Recessive isolated growth hormone deficiency and mutations in the ghrelin receptor. J. Clin. Endocrinol. Metab. 94, 4334-4341.

Park, S., Jiang, H., Zhang, H., and Smith, R. G. (2012). Modification of ghrelin receptor signaling by somatostatin receptor-5 regulates insulin release. Proc. Natl. Acad. Sci. U.S.A. 109, 19003-19008.

Petersen, P. S., Woldbye, D. P. D., Madsen, A. N., Egerod, K. L., Jin, C., Lang, M., et al. (2009). In vivo characterization of high Basal signaling from the ghrelin receptor. Endocrinology 150, 4920-4930.

Petersenn, S. (2002). Structure and regulation of the growth hormone secretagogue receptor. Minerva Endocrinol. 27, 243-256.

Pong, S. S., Chaung, L. Y., Dean, D. C., Nargund, R. P., Patchett, A. A., and Smith, R. G. (1996). Identification of a new G-protein-linked receptor for growth hormone secretagogues. Mol. Endocrinol. 10, 57-61.

Portelli, J., Thielemans, L., Ver Donck, L., Loyens, E., Coppens, J., Aourz, $\mathrm{N}$., et al. (2012). Inactivation of the constitutively active ghrelin receptor attenuates limbic seizure activity in rodents. Neurotherapeutics 9 , 658-672.

Poulin, B., Maccario, H., Thirion, S., Junoy, B., Boyer, B., Enjalbert, A., et al. (2009). Ubiquitination as a priming process of PKC alpha and PKC epsilon degradation in the alphaT3-1 gonadotrope cell line. Neuroendocrinology 89, 252-266.

Rediger, A., Piechowski, C. L., Habegger, K., Grüters, A., Krude, H., Tschöp, M. H., et al. (2012). MC4R dimerization in the paraventricular nucleus and GHSR/MC3R heterodimerization in the arcuate nucleus: is there relevance for body weight regulation? Neuroendocrinology 95, 277-288.

Rediger, A., Piechowski, C. L., Yi, C. X., Tarnow, P., Strotmann, R., Grüters, A., et al. (2011). Mutually opposite signal modulation by hypothalamic heterodimerization of ghrelin and melanocortin-3 receptors. J. Biol. Chem. 286, 39623-39631.

Reiter, E., Ahn, S., Shukla, A. K., and Lefkowitz, R. J. (2012). Molecular 
mechanism of $\beta$-arrestin-biased agonism at seven-transmembrane receptors. Annu. Rev. Pharmacol. Toxicol. 52, 179-197.

Roche, C., Rasolonjanahary, R., Thirion, S., Goddard, I., Fusco, A., Figarella-Branger, D., et al. (2012). Inactivation of transcription factor pit-1 to target tumoral somatolactotroph cells. Hum. Gene Ther. 23, 104-114.

Schellekens, H., Van Oeffelen, W. E., Dinan, T. G., and Cryan, J. F. (2013). Promiscuous dimerization of the growth hormone secretagogue receptor (GHSR1a) attenuates ghrelin-mediated signaling. J. Biol. Chem. 288, 181-191.

Schwartz, T. W., Frimurer, T. M., Holst, B., Rosenkilde, M. M., and Elling, C. E. (2006). Molecular mechanism of 7TM receptor activation-a global toggle switch model. Annu. Rev. Pharmacol. Toxicol. 46, 481-519.

Seachrist, J. L., and Ferguson, S. S. (2003). Regulation of G protein-coupled receptor endocytosis and trafficking by Rab GTPases. Life Sci. 74, 225-235.

Seifert, R., and Wenzel-Seifert, K. (2002). Constitutive activity of G-protein-coupled receptors: cause of disease and common property of wild-type receptors. Arch. Pharmacol. 366, 381-416.

Shukla, A. K., Xiao, K., and Lefkowitz, R. J. (2011). Emerging paradigms of $\beta$-arrestin-dependent seven transmembrane receptor signaling. Trends Biochem. Sci. 36, 457-469.

Sivertsen, B., Lang, M., Frimurer, T. M., Holliday, N. D., Bach, A., Els, S., et al. (2011). Unique interaction pattern for a functionally biased ghrelin receptor agonist. J. Biol. Chem. 286, 20845-20860.

Smit, M. J., Vischer, H. F., Bakker, R. A., Jongejan, A., Timmerman, H., Pardo, L., et al. (2007). Pharmacogenomic and structural analysis of constitutive $\mathrm{g}$ protein-coupled receptor activity.
Annu. Rev. Pharmacol. Toxicol. 47, 53-87.

Stengel, A., and Taché, Y. (2012). Ghrelin-a pleiotropic hormone secreted from endocrine $\mathrm{x} / \mathrm{a}$-like cells of the stomach. Front. Neurosci. 6:24. doi: 10.3389/fnins.2012 00024

Valentin-Hansen, L., Holst, B. Frimurer, T. M., and Schwartz, T. W. (2012). PheVI:09 (Phe6.44) as a sliding microswitch in seven-transmembrane (7TM) G protein-coupled receptor activation. J. Biol. Chem. 287, 43516-43526.

Wang, H. J. (2004). Ghrelin receptor gene: identification of several sequence variants in extremely obese children and adolescents, healthy normal-weight and underweight students, and children with short normal stature. J. Clin. Endocrinol. Metab. 89, 157-162.

Conflict of Interest Statement: The authors declare that the research was conducted in the absence of any commercial or financial relationships that could be construed as a potential conflict of interest.

Received: 31 December 2012; accepted: 09 May 2013; published online: 29 May 2013.

Citation: Mear Y, Enjalbert $A$ and Thirion S (2013) GHS-R1a constitutive activity and its physiological relevance. Front. Neurosci. 7:87. doi: 10.3389/fnins. 2013.00087

This article was submitted to Frontiers in Neuroendocrine Science, a specialty of Frontiers in Neuroscience.

Copyright (C) 2013 Mear, Enjalbert and Thirion. This is an open-access article distributed under the terms of the Creative Commons Attribution License, which permits use, distribution and reproduction in other forums, provided the original authors and source are credited and subject to any copyright notices concerning any third-party graphics etc. 